\title{
NUMERICAL AND ASYMPTOTIC MODELING OF A FILTRATION PROBLEM WITH THE INITIAL DEPOSIT
}

\author{
Ludmila I. Kuzmina', Yuri V. Osipov', Yuri P. Galaguz ${ }^{2}$ \\ ${ }^{1}$ National Research University Higher School of Economics, Moscow, RUSSIA \\ ${ }^{2}$ National Research Moscow State University of Civil Engineering, Moscow, RUSSIA
}

\begin{abstract}
The study of filtration as one of the problems of underground hydromechanics is necessary for the design and construction of tunnels, underground and hydraulic structures. Deep bed filtration of suspension in a porous medium with variable porosity and permeability and with an initial deposit is considered. An asymptotic solution to a model with small limit deposit is constructed; the asymptotics is compared with numerical calculation.
\end{abstract}

Keywords: filtration problem, suspension, filtration coefficient, size-exclusion particle capture, asymptotic solution, numerical calculation

\section{ЧИСЛЕННОЕ И АСИМПТОТИЧЕСКОЕ МОДЕЛИРОВАНИЕ ЗАДАЧИ ФИЛЬТРАЦИИ С ПЕРВОНАЧАЛЬНЫМ ОСАДКОМ}

\author{
Л.И. Кузьмина 1 , Ю.В. Осипов ${ }^{2}$, Ю.П. Галагуз ${ }^{2}$ \\ ${ }^{1}$ Национальный исследовательский университет «Высшая школа экономики», г. Москва, РОССИЯ \\ ${ }^{2}$ Национальный исследовательский Московский государственный строительный университет, \\ г. Москва, РОССИЯ
}

\begin{abstract}
Аннотация: Исследование фильтрации как одной из задач подземной гидромеханики необходимо при проектировании и строительстве туннелей, подземных и гидротехнических сооружений. Рассматривается модель фильтрации суспензии в пористой среде с переменными пористостью и проницаемостью и с первоначальным осадком. Строится асимптотическое решение при малом предельном осадке, асимптотика сравнивается с численным расчетом задачи.
\end{abstract}

Ключевые слова: суспензия, пористая среда, коэффициент фильтрации, геометрический механизм захвата частиц, асимптотика, численное решение

\section{INTRODUCTION}

Filtration problems are essential in the design and construction of tunnels, underground and hydraulic structures, as well as for the concreting of friable rocks. During the filtration of the suspension in the porous medium some of the fine particles pass through the pores, and part of them is stuck in a porous medium and forms a deposit [1-4]. Different physical models are used for description of the filtration depending on the properties of the suspension and the porous medium and the nature of their interaction [5-12].

In this paper the filtration of a suspension in a porous medium with an initial deposit is consid- ered. This is a step of a periodic process, accompanied by the accumulation of the deposit. Filtration of the suspension (forward flow) is replaced by the filter wash with clean water (back flow), then the suspension enters the filter again and displaces water, etc. [13, 14]. Mechanical and geometric size-exclusion model of particle retention assumes that the suspended particles of the suspension pass freely through the large pores and get stuck at the inlets of pores smaller than the particle size. In contrast to the standard models, we assume that the porosity and permeability of the porous medium change with the increase of the deposit. With the increase of deposit the number of free small 
pores decreases and deposit accumulation slows down. After a long-term filtration all the small pores are clogged and the suspended particles pass freely through the porous medium without retention.

Concentrations of suspended and retained particles of the suspension satisfy a quasi-linear hyperbolic system of two differential equations in partial derivatives. The first equation is the equation of mass transfer of suspension particles, the second kinetic equation describes the deposit growth in porous media [15]. The conditions at the filter inlet and at the initial time determine the unique solution to the problem. Exact and asymptotic solutions of the filtration problems for a variety of filter coefficients and boundary conditions are obtained in [15-19].

The outline of the paper is as follows. Section 2 presents the mathematical model of deep bed filtration with the initial deposit. In Section 3 a global asymptotic solution is constructed for a small limit deposit. The asymptotics of the boundary line of two phases, which is a mobile concentration front of suspended particles, is determined. Section 4 presents numerical calculations and the comparison of the asymptotic and numerical solutions. The results are summarized in Section 5.

\section{THE MATHEMATICAL MODEL}

A system for one-dimensional model of deep bed filtration of suspension in a porous medium with variable porosity $g(S)$ and permeability $f(S)$ consists of two equations

$$
\begin{gathered}
\frac{\partial(g(S) C)}{\partial t}+\frac{\partial(f(S) C)}{\partial x}+\frac{\partial S}{\partial t}=0 ; \\
\frac{\partial S}{\partial t}=\Lambda(S) C .
\end{gathered}
$$

Here $\Lambda(S)$ is the filtration coefficient; $g(S), f(S), \Lambda(S)$ are the smooth non-negative functions.
It is assumed that the suspension with constant concentration of the suspended particles is injected at the filter inlet $x=0$. At the initial time $t=0$ there are no suspended particles in the porous medium and the concentration of the retained particles $s_{0}(x)$ is distributed unevenly over the filter. Appropriate initial and boundary conditions are

$$
\begin{gathered}
\left.C\right|_{x=0}=1 ; \\
\left.C\right|_{t=0}=0 ;\left.\quad S\right|_{t=0}=s_{0}(x) .
\end{gathered}
$$

Conditions (3) and (4) determine a unique solution in the domain $\Omega=\{(x, t): 0<x<1, t>0\}$. The concentration front of the suspended particles moves in porous media with the velocity

$$
v(x)=\frac{f\left(s_{0}(x)\right)}{g\left(s_{0}(x)\right)}
$$

along the characteristic $\Gamma$, given by the equation

$$
\frac{d x}{d t}=v(x), x(0)=0 .
$$

The boundary $\Gamma$ of the two phases satisfies the equation

$$
t_{\Gamma}(x)=\int_{0}^{x} \frac{g\left(s_{0}(y)\right)}{f\left(s_{0}(y)\right)} d y
$$

Since the conditions (3) and (4) have not been agreed at the origin, according to the theory of characteristics [20] on the boundary $\Gamma$ the solution $C$ has a strong discontinuity; and the solution $S$ has a weak discontinuity (the break of the derivative). Behind the concentration front in $\Omega_{S}$ the solution is positive $C>0, S>0$; ahead of the front in $\Omega_{W}$ the solution $C=0, S=s_{0}(x)$. On the concentration front $\Gamma=\left\{t=t_{\Gamma}(x), 0 \leq x \leq 1\right\}$ the retained particles concentration 


$$
\left.S\right|_{t=t_{\Gamma}(x)}=s_{0}(x) \text {. }
$$

In $\Omega_{S}$ the solution of the Goursat problem (1) (3) (8) coincides with the solution of the original problem (1) - (4).

The system (1), (2) with constant coefficients

$$
\begin{gathered}
\frac{\partial C}{\partial t}+\frac{\partial C}{\partial x}+\frac{\partial S}{\partial t}=0 \\
\frac{\partial S}{\partial t}=\lambda C, \lambda>0
\end{gathered}
$$

has a two-phase boundary line $t=x$. The conditions (3) and (4) determine an exact solution

$$
\begin{gathered}
C(x, t)= \begin{cases}e^{-\lambda x}, & t \geq x ; \\
0, & t<x ;\end{cases} \\
S(x, t)= \begin{cases}\lambda(t-x) e^{-\lambda x}+s_{0}(x), & t \geq x ; \\
s_{0}(x), & t<x .\end{cases}
\end{gathered}
$$

In general, the problem (1) - (4) does not have an analytic solution. Below an asymptotics is constructed, and the results of numerical simulation are provided.

\section{ASYMPTOTIC SOLUTION FOR A SMALL LIMIT DEPOSIT}

Let the filtration coefficient $\Lambda(S)>0$ for $0 \leq S<S_{M}$ and $\Lambda\left(S_{M}\right)=0$. In this case, the concentration of the retained particles $S(x, t)$ does not exceed the limit value $S_{M}$. The blocking filtration coefficient has the form

$$
\begin{aligned}
& \Lambda(S)=\lambda\left(S_{M}-S\right)+\lambda_{2}\left(S_{M}-S\right)^{2}+O\left(S_{M}-S\right)^{3} \\
& \text { Let } \\
& \qquad \begin{array}{l}
g(S)=g_{0}+g_{1} S+O\left(S^{2}\right) \\
f(S)=f_{0}+f_{1} S+O\left(S^{2}\right)
\end{array}
\end{aligned}
$$

The asymptotic solution for a small limit deposit $S_{M}$ is constructed in the form

$$
\begin{aligned}
& C=1+S_{M} c_{1}+O\left(S_{M}^{2}\right) ; \\
& S=S_{M} s_{1}+S_{M}^{2} S_{2}+O\left(S_{M}^{3}\right) .
\end{aligned}
$$

Substituting the expansions (10), (11) in equations (1), (2) and equating terms with the same powers of $S_{M}$, we obtain a system of recurrent equations

$$
\begin{gathered}
\frac{\partial s_{1}}{\partial t}=\lambda\left(1-s_{1}\right) \\
g_{0} \frac{\partial c_{1}}{\partial t}+f_{0} \frac{\partial c_{1}}{\partial x}+g_{1} \frac{\partial s_{1}}{\partial t}+f_{1} \frac{\partial s_{1}}{\partial x}+\frac{\partial s_{1}}{\partial t}=0 \\
\frac{\partial s_{2}}{\partial t}=\lambda\left(1-s_{1}\right) c_{1}-\lambda s_{2}+\lambda_{2}\left(1-s_{1}\right)^{2}
\end{gathered}
$$

Using the inequality $s_{0}(x) \leq S_{M}$ the condition (8) can be written as

$$
\left.S\right|_{t=t_{\Gamma}(x)}=S_{M} q(x), 0 \leq q(x) \leq 1 .
$$

Conditions defining the unique solution of the system (12)-(14) follow from (3), (15):

$$
\begin{gathered}
\left.s_{1}\right|_{t=t_{\Gamma}(x)}=q(x) ; \\
\left.c_{1}\right|_{x=0}=0 ; \\
\left.s_{2}\right|_{t=t_{\Gamma}(x)}=0 .
\end{gathered}
$$

The asymptotics of the two phase boundary line $\Gamma$ can be obtained by expanding the integrand in (7) in a series of powers of $S_{M}$

$$
\begin{aligned}
& \frac{g\left(q(y) S_{M}\right)}{f\left(q(y) S_{M}\right)}=\frac{g_{0}+g_{1} q(y) S_{M}+O\left(S_{M}^{2}\right)}{f_{0}+f_{1} q(y) S_{M}+O\left(S_{M}^{2}\right)}= \\
& =\frac{g_{0}}{f_{0}}+\frac{g_{1} f_{0}-g_{0} f_{1}}{f_{0}^{2}} q(y) S_{M}+O\left(S_{M}^{2}\right) .
\end{aligned}
$$

Substitution of the expansion (19) into the integral (7) gives 


$$
t_{\Gamma}(x)=\alpha x+\beta S_{M} \int_{0}^{x} q(y) d y+O\left(S_{M}^{2}\right)
$$

where $\alpha=g_{0} / f_{0}, \beta=\left(g_{1} f_{0}-g_{0} f_{1}\right) / f_{0}^{2}$.

The solution of the equation (12), (16)

$$
s_{1}=1-(1-q(x)) e^{-\lambda\left(t-t_{\Gamma}(x)\right)}
$$

After the substitution of (21) into (13) the solution of (13) can be written in the form

$$
c_{1}=e^{-\lambda t} u(x) .
$$

The function $u(x)$ satisfies the equation

$$
\begin{gathered}
u^{\prime}-\lambda \alpha u+e^{\lambda t_{\Gamma}(x)} K(x)=0, u(0)=0, \\
K(x)=\frac{\left(g_{1}+1-\alpha f_{1}\right) \lambda(1-q(x))+f_{1} q^{\prime}(x)}{f_{0}} .
\end{gathered}
$$

From (20) the function

$$
u=-e^{\lambda t_{\Gamma}(x)} \int_{0}^{x} K(y) d y
$$

is the solution of (23) with an accuracy $O\left(S_{M}\right)$. From (24), (22)

$$
c_{1}=-e^{-\lambda\left(t-t_{\Gamma}(x)\right)} \int_{0}^{x} K(y) d y .
$$

Substitution of the solutions (21) and (25) into equation (14) gives with an accuracy $O\left(S_{M}\right)$

$$
\begin{aligned}
& \frac{\partial s_{2}}{\partial t}=-\lambda s_{2}+(1-q(x)) e^{-2 \lambda\left(t-t_{\Gamma}(x)\right)} . \\
& \cdot\left(-\lambda \int_{0}^{x} K(y) d y+\lambda_{2}(1-q(x))\right) .
\end{aligned}
$$

The solution of (26) with the condition (18)

$$
\begin{aligned}
& s_{2}=\left(e^{-\lambda\left(t-t_{\Gamma}(x)\right)}-e^{-2 \lambda\left(t-t_{\Gamma}(x)\right)}\right)(1-q(x)) . \\
& \cdot\left(-\int_{0}^{x} K(y) d y+\frac{\lambda_{2}}{\lambda}(1-q(x))\right) .
\end{aligned}
$$

The functions (21), (25), (27) are the main terms of the asymptotic expansions (11). These expansions exactly satisfy the conditions (3) and (4); equation (1) is satisfied with accuracy $O\left(S_{M}^{2}\right)$, equation (2) - with accuracy $O\left(S_{M}^{3}\right)$.

\section{NUMERICAL MODELING}

The numerical calculation is performed by finite difference method for explicit TVD-scheme with superbee limiter function [21] for

$$
\begin{gathered}
g(S)=1+3 S, \quad f(S)=1+2 S, \\
s_{0}(x)=q(x) S_{M}, \quad q(x)=0.5(1-x), \\
S_{M}=0.5, \quad S_{M}=0.1, \\
\lambda=\lambda_{2}=1 .
\end{gathered}
$$

The following figures illustrate the asymptotics (dashed line) and the numerical solution (solid line).

The figures show the break of suspended particles concentration $C(x, t)$ and the loss of smoothness of retained particles concentration $S(x, t)$ on the two-phase boundary $\Gamma$.

\section{CONCLUSION}

The filtration problem with the initial deposit is a generalization of deep bed filtration of the suspension in a porous medium with sizeexclusion particle retention mechanism [15]. For a uniformly distributed initial deposit $s_{0}(x)=s_{0}=$ const the substitution $\tilde{S}=S-s_{0}$ reduces the problem to the standard model. In case of the uneven initial deposit $s_{0}(x)$ the global asymptotic solution is constructed for a small limit deposit $S_{M}$. 

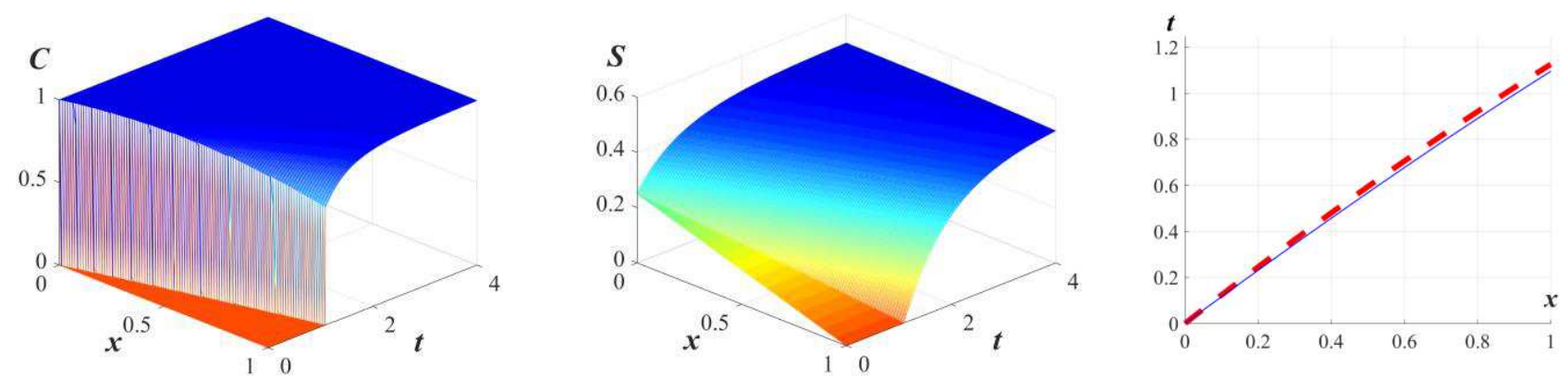

Figure 1. 3-D graphs of concentrations and the boundary of the two phases for $S_{M}=0.5$.

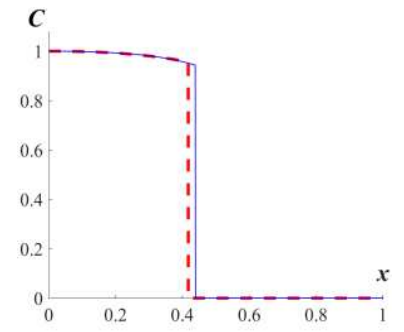

a) $t=0.5$

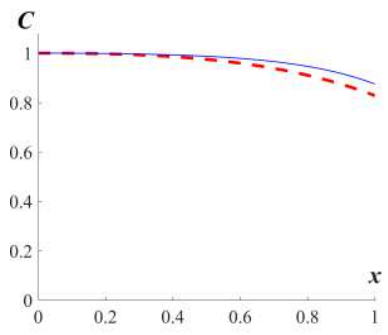

b) $t=1.5$

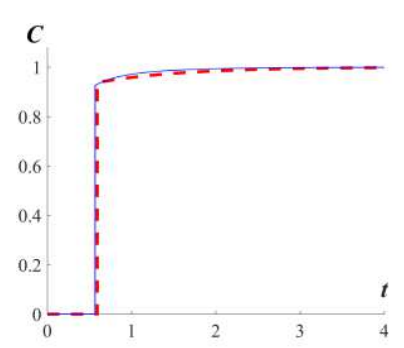

c) $x=0.5$

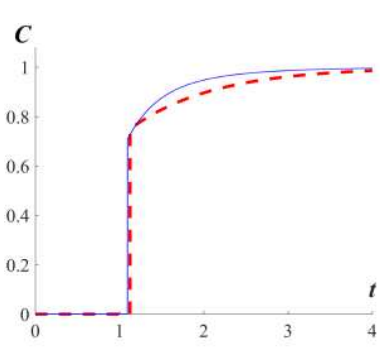

d) $x=1$

Figure 2. Graphs of the suspended particles concentration for $S_{M}=0.5$.

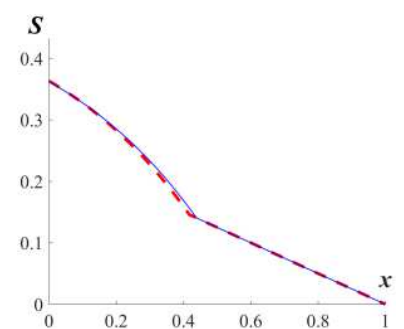

a) $t=0.5$

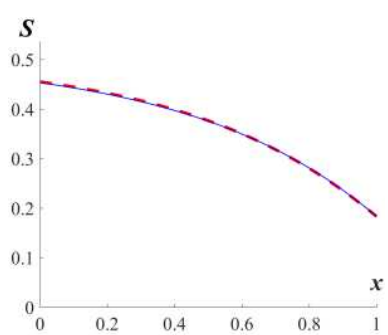

b) $t=1.5$

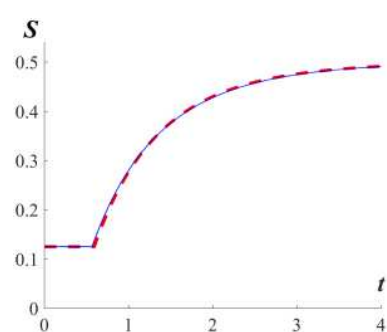

c) $x=0.5$

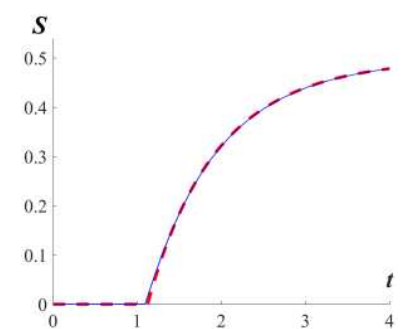

d) $x=1$

Figure 3. Graphs of the retained particles concentration for $S_{M}=0.5$.

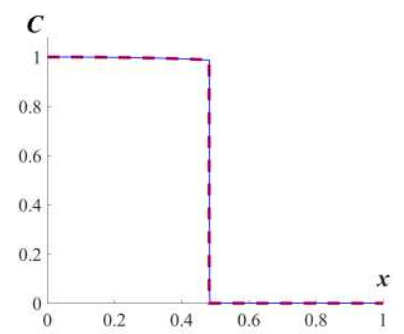

a) $t=0.5$

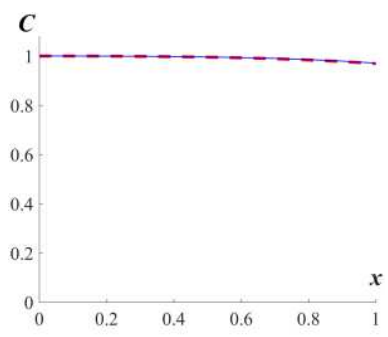

b) $t=1.5$

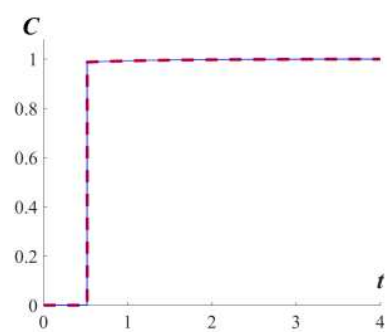

c) $x=0.5$

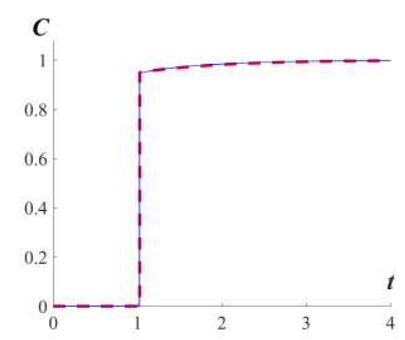

d) $x=1$

Figure 4. Graphs of the suspended particles concentration for $S_{M}=0.1$.

The asymptotics is compared with a numerical solution of the problem. Figures $1-3$ show that the asymptotics gives good approximation of the solution for relatively large limit deposit
$S_{M}=0.5$; with decreasing limit deposit an asymptotic approximation error tends to zero rapidly (see fig. 4,5 ). 


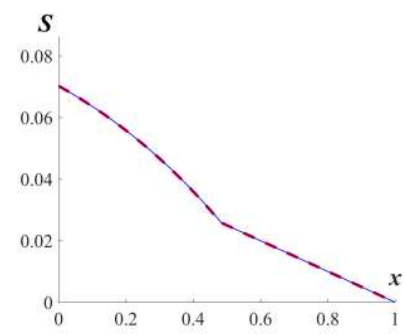

a) $t=0.5$

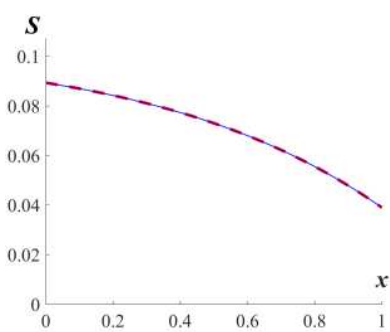

b) $t=1.5$

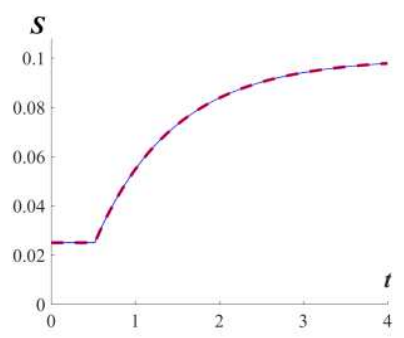

c) $x=0.5$

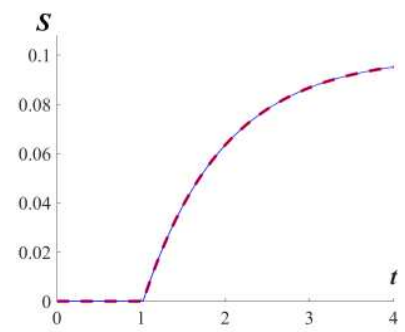

d) $x=1$

Figure 5. Graphs of the retained particles concentration for $S_{M}=0.1$.

The asymptotic and numerical modeling can be used in the planning and analysis of experimental studies [22].

\section{REFERENCES}

1. Khilar K., Fogler S. Migration of Fines in Porous Media, Kluwer Academic Publishers, Dordrecht, 1998.

2. Tien C. Principles of Filtration, Elsevier, Oxford, 2012.

3. Barenblatt G.I., Entov V.M., Ryzhik V.M. Theory of Fluid Flows Through Natural Rocks, Kluwer Academic Publishers, Dordrecht, 1990.

4. Bedrikovetsky P. Mathematical Theory of Oil and Gas Recovery with Applications to ex-USSR Oil and Gas Fields, Kluwer Academic Publishers, Dordrecht, 1993.

5. Logan D.J. Transport Modelling in Hydrogeochemical Systems, Springer, N.Y., 2001.

6. Mays D., Hunt J.R. Hydrodynamic Aspects of Particle Clogging in Porous Media. // Environmental Science \& Technology, 39, 2005, pp. 577-584.

7. Domga R., Tchatchueng J.B., TogueKamga F., Noubactep C. Discussing Porosity Loss of FeO Packed Water Filters at Ground Level. // Chemical Engineering Journal, 263 (2015) 127-134.

8. Jegatheesan V., Vigneswaran S. Deep Bed Filtration: Mathematical Models and Observations. // Critical Reviews in Environmental Science \& Technology, 35(6), 2005, pp. 515-569.
9. Tien C., Ramarao B.V. Granular Filtration of Aerosols and Hydrosols. 2nd ed. Elsevier, Amsterdam, 2007.

10. Chrysikopoulos C.V., Syngouna V.I. Effect of Gravity on Colloid Transport Through Water-Saturated Columns Packed with Glass Heads: Modeling and Experiments. // Environmental Science \& Technology, 48, 2014, pp. 6805-6813.

11. Payatakes A.S., Rajgopalan R., Tien C. Application of Porous Medium Models to the Study of Deep bed Filtration. // Canadian Journal of Chemical Engineering, 52, 1974, pp. 727-731.

12. Santos A., Araujo J.A. Modeling Deep Bed Filtration Considering Limited Particle Retention. // Transport in Porous Media, 108(3), 2015, pp. 697-712.

13. Kuzmina L.I., Osipov Yu.V. Filtration of Forward and Back Flow of Suspension in Porous Media. // International Journal for Computational Civil and Structural Engineering, 12(3), 2016, pp. 145-150.

14. Galaguz Y.P., Safina G.L. Modeling of Particle Filtration in a Porous Medium with Changing Flow Direction. // Procedia Engineering, 153, 2016, pp. 157-161.

15. You Z., Bedrikovetsky P., Kuzmina L. Exact Solution for Long-Term Size Exclusion Suspension-Colloidal Transport in Porous Media. // Abstract and Applied Analysis, 2013, 2013, pp. 1-9.

16. Herzig J.P., Leclerc D.M., Le Goff P. Flow of Suspensions Through Porous Media - Application to Deep Filtration. // Journal of Industrial \& Engineering Chemistry, 62(8), 1970, pp. 8-35. 
17. Vyazmina E.A., Bedrikovetskii P.G., Polyanin A.D. New Classes of Exact Solutions to Nonlinear Sets of Equations in the Theory of Filtration and Convective Mass Transfer. // Theoretical Foundations of Chemical Engineering, 41(5), 2007, pp. 556-564.

18. You Z., Osipov Y., Bedrikovetsky P., Kuzmina L. Asymptotic Model for Deep Bed Filtration. // Chemical Engineering Journal, 258, 2014, pp. 374-385.

19. Kuzmina L.I., Osipov Yu.V. Asymptotic Solution for Deep Bed filtration with small deposit, Procedia Engineering, 111 (2015) 491-494.

20. Rozhdestvenskii B.L., Yanenko N.N. Systems of Quasilinear Equations and Their Applications to Gas Dynamics, American Mathematical Society, Providence, RI, 1983.

21. Toro E.F. Riemann Solvers and Numerical Methods for Fluid Dynamics, 3 ed., Springer, Dordrecht, 2009.

22. Bedrikovetsky P.G., Marchesin D., Checaira F., Serra A.L., Resende E. Characterization of Deep Bed Filtration System from Laboratory Pressure Drop Measurements. // Journal of Petroleum Science and Engineering, 32(3), 2001, pp. 167-177.

Ludmila I. Kuzmina, Candidate of Physical and Mathematical Sciences, Associate Professor, Department of Applied Mathematics, National Research University Higher School of Economics, 101000, Russia, Moscow, Myasnitskaya st., 20, tel. +7(495) $7729590 * 15219$, e-mail: 1kuzmina@hse.ru.

Yuri V. Osipov, Candidate of Physical and Mathematical Sciences, Associate Professor, Department of Applied Mathematics, National Research Moscow State University of Civil Engineering, 129337, Russia, Moscow, Yaroslavskoe Shosse, 26, tel. +7(499)1835994, e-mail: yuriosipov@mail.ru.

Yuri P. Galaguz, Senior Lecturer, Department of Applied Mathematics, National Research Moscow State University of Civil Engineering, 129337, Russia, Moscow, Yaroslavskoe Shosse, 26, tel. +7 (499) 1835994, e-mail: yuri.galaguz@gmail.com.
Кузьмина Людмила Ивановна, доцент, кандидат физико-математических наук, Департамент прикладной математики, Национальный исследовательский университет «Высшая школа экономики»; 101000, г. Москва, ул. Мясницкая, д. 20, тел. +7(495) 772-95-90*15219; e-mail: 1kuzmina@hse.ru;

Осипов Юрий Викторович, доцент, кандидат физикоматематических наук, заведующий кафедрой прикладной математики, Национальный исследовательский Московский государственный строительный университет (НИУ МГСУ); 129337, Россия, г. Москва, Ярославское шоссе, д. 26; тел. +7(499) 183-59-94;

e-mail: yuri-osipov@mail.ru.

Галагуз Юрий Петрович, старший преподаватель кафедры прикладной математики, Национальный исследовательский Московский государственный строительный университет (НИУ МГСУ); 129337, Россия, г. Москва, Ярославское шоссе, д. 26;

тел. +7(499) 183-59-94;

e-mail: yuri.galaguz@gmail.com. 